\title{
Self-expandable metallic stents in oesophago-respiratory fistulas treatment in neoplasms - case reports and literature review
}

The authors declare no finacial disclosure

\begin{abstract}
Self-expandable metallic stents (SEMS) insertion to the oesophagus is the method of choice in palliative treatment of malignant oesophago-respiratory fistulas (ERF). ERF evolve as a result of $0.2-5 \%$ of advanced oesopghageal or lung cancer. They also appear after radiotherapy. EFR are serious and lethal complications. SEMS insertion is an effective, safe, technically simple and minimally invasive solution. Potential complications of SEMS include thoracic pain, bleeding, perforation, stent migration, tumour overgrowth or ingrowth and food bolus impaction. The article presents three cases of patients with advanced lung cancer with EFR subjected to SEMS insertion procedure in our centre.
\end{abstract}

Key words: oesophageal cancer, fistula, self-expandable metallic stents

\section{Introduction}

The oesophago-respiratory fistulas (EFR) are formed between the lumen of the oesopghagus and bronchus or trachea due to the development and proliferation of oesophageal or extraoesophageal carcinoma. Occasionally, fistulas develop between the oesophagus and mediastinum, aorta, pleura or tumour cavity. In the group of 1943 patients with oesophageal cancer, EFR were diagnosed in $5 \%$ of them, whereas in the group of 5714 bronchial cancer patients, EFR were found in $0.2 \%$ of patients [1]. EFR can develop in about $5.8 \%$ of patients after radiotherapy [2]. The development of oesophageal carcinoma as well as proliferation of bronchial cancer into the oesophagus cause the symptoms of dysphagia in the first instance. The development of EFR seriously impacts patients' survival, which may be limited to weeks [3]. EFR symptoms include choke and cough associated with eating and drinking, dysphagia and dyspnoea [4]. SEMS implantation is an effective, safe and relatively simple method of choice in palliative treatment of patients with EFR [4-8]. SEMS have been used for ERF since the early 1990s, when they replaced rigid plastic stents [4, 5]. SEMS insertion effectively closes fistulas in $88.9-96 \%$ of patients [4, 6, 9-12]. In selected cases, endoscopic double stenting (airway and esophageal) is performed [13, 14]. However, SEMS implantation could lead to complications, which occur in $10-30 \%$ of cases $[4,7,12]$. They may be divided into two groups. Early complications, occurring up to 30 days from SEMS implantation, include: pain, vomiting, bleeding, malposition/migration, perforation and dysphagia. Late complications, occurring after 30 days, comprise: tumour overgrowth and ingrowth, migration, haemorrhage, fistulas, food impaction and esophagitis $[4,7,12]$. Stent migration is a common complication [9]. It may cause gastrointestinal tract obstruction [15]. Stents are 
usually applied in analgosedation under endoscopic and/or fluoroscopic control. There are no statistical significant differences between these two methods [7]. In 95\% of patients, SEMS implantation causes immediate improvement and enables oral nutrition $[4-6,9,11,12]$. SEMS implantation improves the quality of life and increases the lifespan $[6,11,12]$. The successful stent placement enables the patient to receive palliative chemo- or radiotherapy [13].

\section{Case reports}

\section{Case 1}

A 58 year-old male suffering from squamous cell carcinoma of the mediastinum, after radical teleradiotherapy in 2013, brachytherapy in 2014, and with metastases to mediastinal and cervical lymph nodes, was admitted to the hospital because of increased dyspnoea, haemoptysis, choke and cough during eating and drinking. Diagnostic tests including computed tomography of the chest revealed oesophago-respiratory fistula, which was also confirmed at endoscopic examination of the upper gastrointestinal tract. SEMS insertion to the oesophagus was performed in analgosedation under fluoroscopic control. Stent location was controlled and corrected under endoscopic guidance, dilation of stenosis and fistula complete closure were obtained. The placement of the stent significantly improved the patient's symptoms. No significant early complications were observed. The patient was allowed oral nutrition. He was discharged in a good general condition.

\section{Case 2}

A 51 year-old male with non-small cell lung carcinoma of the left lung was admitted after chemo- and radiotherapy due to dysphagia, odynophagia and bad general condition. Computed tomography of the chest revealed connection between the oesophagus and tumour cavity. The tumour infiltrated the parietal pleura, main left bronchus, trachea, penetrated the mediastinum and infiltrated the oesophagus. The endoscopic examination of the upper digestive tract showed a big, oval fistula to the tumour cavity, located centrally, inside the oesophagus, at a depth of $22 \mathrm{~cm}$. The constricted lumen of the infiltrated oesophagus was located laterally. The stenosed segment of the oesophagus was overcome with the standard diameter endoscope. The SEMS implantation was performed in analgosedation, under fluoroscopic control, along the

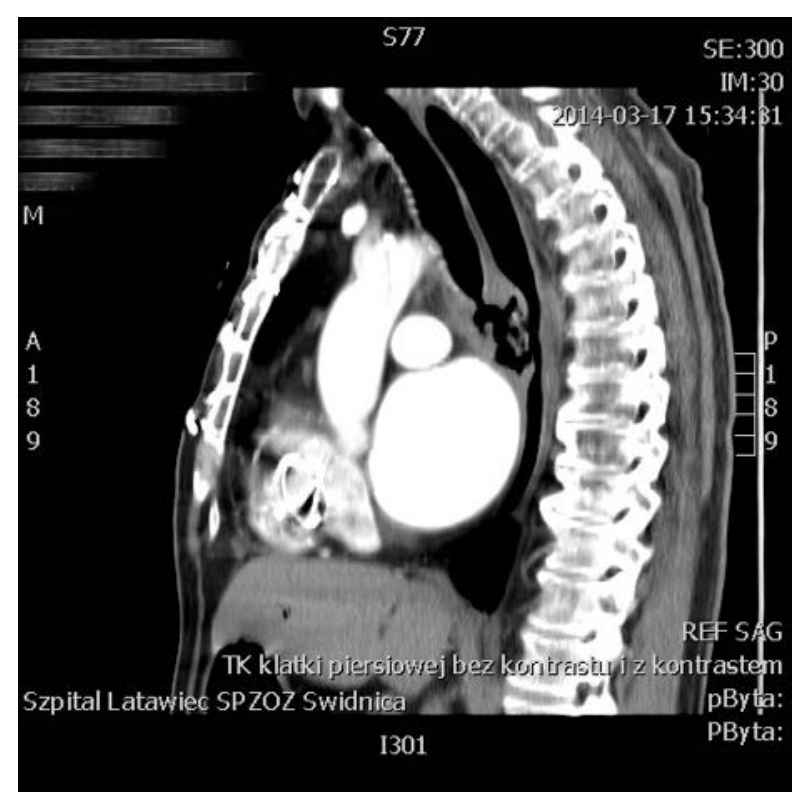

Figure 1. Oesophageal fistula in lateral reconstruction on computed tomography of the thoracic cavity

Savary-Gillard guide wire. Endoscopic control revealed fistula's total closure and dilation of the oesophageal lumen. The patient's condition improved and the majority of complaints were dealt with. No significant early complications were observed. The next day, oral nutrition was successfully introduced. The patient was discharged.

\section{Case 3}

A 73 year-old female with non-small cell carcinoma of the right lung was earlier hospitalized in our ward due to dysphagia caused by oesophagus stenosis induced by the growth of the lung tumour. The stenosis was successfully widened with the use of endoscope. After one month, the patient was readmitted because of dysphagia increase, cough and choke associated with eating and drinking. Endoscopic examination of the upper gastrointestinal tract revealed stenosis of the oesophagus and fistula to the respiratory tract. The stenosis was overcome with the endoscope $5.9 \mathrm{~mm}$ in diameter. Along the guide, under fluoroscopic control, in analgosedation, SEMS was inserted. The stent position was controlled under endoscopic guidance. The fistula closure and dilation of the stenosed segment of the oesophagus were confirmed. No significant early complications were observed. The next day, oral nutrition was successfully introduced. The patient was discharged. 


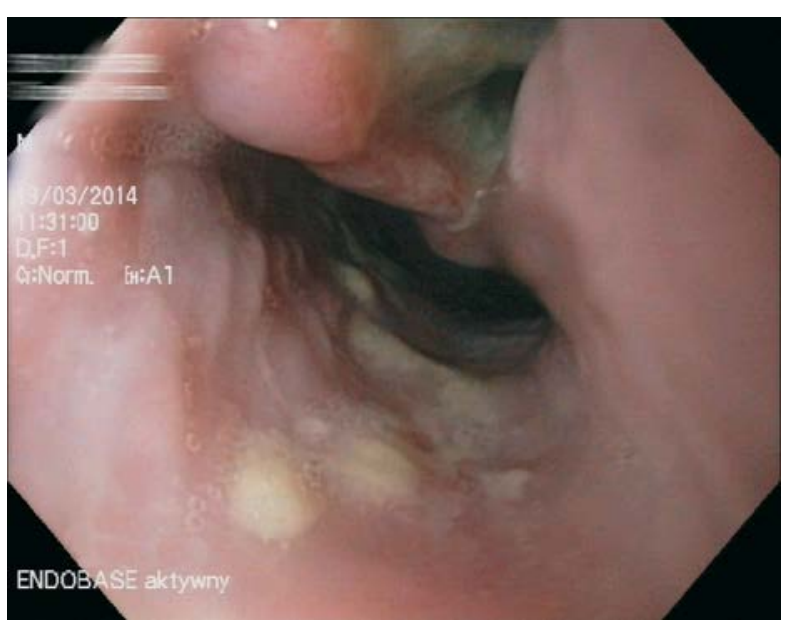

Figure 2. Oesophago-respiratory fistula — endoscopic image

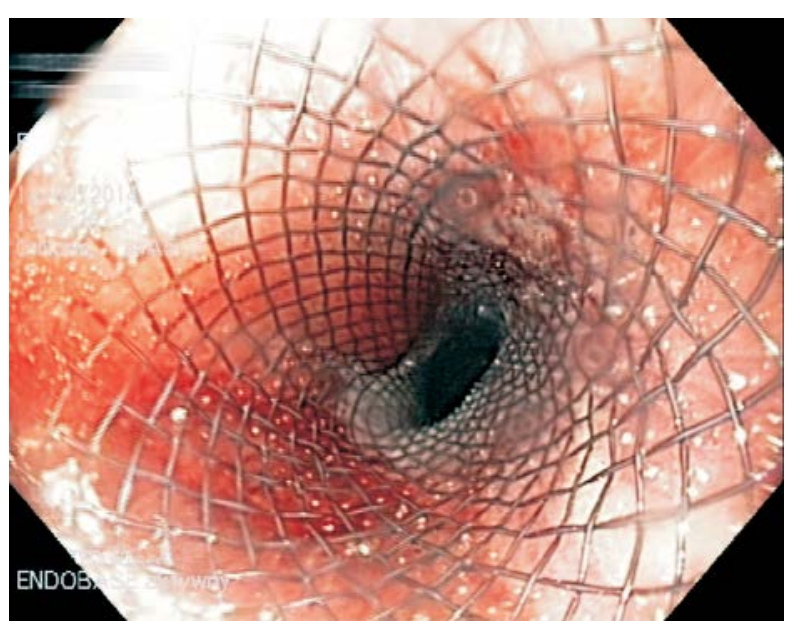

Figure 3. Endoscopic image after SEMS implantation, successful dilation of the stenosed segment of the oesophagus and the fistula closure

\section{Discussion}

Wierzbicki et al. [4] described 14 patients with EFR caused by carcinoma, in whom 15 SEMS were inserted. A good early effect was observed in 12 of them. In two patients, after several months, the authors observed the tumour overgrowth, which caused its damage with argon plasma coagulation. In two other patients, the authors found fistula recurrence, and in one case, retrial of a new stent application was possible. The longest observed survival period was 13 months [4].

Turkyilmaz et.al. described 14 cases of patients in whom, in the years 2003-2008, SEMS were implanted due to ERF. Fistula closure was achieved in all 14 patients. No significant complications were observed. The mean survival time after SEMS implantation was 11.2 weeks. The average time of post implantation hospitalization was 3.7 days [3].

Balazs et.al described data collected at one centre in which, in the years 1984-2004, 264 cases of ERF were diagnosed. SEMS efficient implantation was achieved in 188 cases. The authors reported one lethal complication. In the second group of patients, 25 gastrostomies, 1 jejunostomy and 1 percutaneous endoscopic gastrostomy were made. The average survival time in patients after SEMS implantation was 3.4 months. In the remaining group it was 1.1 month. The differences between the two groups were significant [11].

Kim et.al. discussed 9 cases of ERF patients: 6 with oesophageal carcinoma, 2 with lung carcinoma and 1 with Boerhaave Syndrome. Technical success was achieved in 8 cases. In one case, unsuccessful ERF closure was strictly connected with non-complete stent dilation. Clinical success defined as the fistula complete closure within 7 days was achieved in five patients. Four patients were reoperated because of the gap between the stent and the oesophagus in 3 patients, and stent migration in 1 patient. The average survival time after efficient implantation was 78.8 days [12].

Herth et al. described 112 ERF patients, among whom 83 (74\%) presented advanced lung carcinoma and 29 (26\%) suffered from advanced oesophageal carcinoma. The authors implanted SEMS to the oesophagus in 37 patients (33\%). In 65 patients, airway stents were inserted. Both airway and oesophageal stents were used in 10 patients. Seven patients (one with oesophageal stent, two with both the oesophageal and the airway one, and four with airway stents) developed respiratory failure and required transient ventilator support in the intensive care unit. The authors did not observe stents migration. The average survival time of patients with oesophageal SEMS implantation was 262.8 days. The average quality of life (QoL) score before stents implantation was 72 , and after the procedure it amounted to 81 . The difference was statistically significant [14].

The reported cases were the first ones in our centre. We performed the described procedures under fluoroscopic and endoscopic control, in analgosedation. We did not observe any of significant early complications, therefore we confirm that SEMS insertion is an effective, safe and relatively easy method, which improves the quality of life, positively influences its elongation and enables further palliative treatment including radiotherapy. We do recommend SEMS implantation. 


\section{Acknowledgements}

The authors would like to thank Professor Elżbieta Poniewierka for her substantial help and support in the article preparation.

\section{Conflict of interest}

The authors declare no conflict of interest.

\section{References:}

1. Martini N, Goodnert JT, D’Angio GJ, Beattie EJ Jr. Tracheoesophageal fistula due to cancer. J Thorac Cardiovasc Surg 1970; 59: $319-324$.

2. Chen HY, Ma XM, Ye M, Hou YL, Xie HY, Bai YR. Esophageal perforation during or after conformal radiotherapy for esophageal carcinoma. J Radiat Res 2014; 55: 940-947. doi: 10.1093/ jrr/rru031.

3. Turkyilmaz A, Aydin Y, Eroglu A, Bilen Y, Karaoglanoglu N. Palliative management of esophagorespiratory fistula in esophageal malignancy. Surg Laparosc Endosc Percutan Tech 2009; 19: 364-367 . doi: 10.1097/SLE.0b013e3181ba796d.

4. Wierzbicki J, Lewandowski A, Grabowski K, Nabzdyk S. Zastosowanie protez samorozprężalnych w leczeniu przetok $\mathrm{w}$ guzach nowotworowych przełyku. Adv Clin Exp Med 2005; 14: $47-50$.

5. McLoughlin MT, Byrne MF. Endoscopic stenting — where are we now and where can we go? WJG 2008; 14: 3798-3803.

6. Masci E, Viale E, Mangiavillano B et al. Enteral self-expandable metal stent for malignant luminal obstruction of the upper and lower gastrointestinal tract: a prospective multicentric study. J Clin Gastroenterol 2008; 42: 389-394. doi: 10.1097/ MCG.0b013e318033d30a
7. Ferreira F, Bastos P, Ribeiro A et al. A comparative study between fluoroscopic and endoscopic guidance in palliative esophageal stent placement. Dis Esophagus 2012; 25: 608-613. doi: 10.1111/j.1442-2050.2011.01288.x.

8. Meier PN, Manns MP. Advantages of endoscopic stenting for malignant gastrointestinal obstruction. Chirurg 2006; 77: 203-209.

9. Nagaraja V, Cox MR, Eslick GD. Safety and efficacy of esophageal stents preceding or during neoadjuvant chemotherapy for esophageal cancer: a systematic and meta-analysis. J Gastrointest Oncol 2014; 5: 119-126. doi: 10.3978/j.issn.20786891.2014.007.

10. Kim TH, Shin JH, Kim KR, Park JH, Kim JH, Song HY. Treatment of esophagopleural fistulas using covered retrievable expandablemetallic stents. J Vasc Interv Radiol 2014; 25: 623-629. doi: 10.1016/j.jvir.2013.12.015.

11. Balazs A, Galambos Z, Kupcsulik PK. Esophagorespiratory fistulas of tumorous origin. Non-operative managment of 264 cases in a 20-year period. Eur J Cardiothorac Surg 2008; 34: 1103-1107. doi: 10.1016/j.ejcts.2008.06.025.

12. Navaneethan U, Duvuru S, Jagedeesan R et al. Factors associated with 30-day readmission and long-term efficacy of enteral stent placement for malignancy. Surg Endosc 2014; 28: 1194-1201.

13. Schweigert M, Posada-Gozales M, Dubecz A, Ofner D, Muschweck H, Stein HJ. Recurrent oesophageal cancer complicated by tracheo-oesophageal fistula: improved palliation by means of parallel tracheal and oesophageal stenting. Interact Cardiovasc Thorac Surg 2014; 18: 190-196.

14. Herth FJ, Peter S, Baty F, Eberhardt R, Leuppi JD, Chhajed PN. Combinated airway and oesophageal stenting in malignant airway-oesophageal fistulas: a prospective study. Eur Respir J 2010; 36: 1370-1374

15. Wroński K, Orłowski M, Michalak A. Niedrożność jelita cienkiego jako konsekwencja przemieszczenia protezy przełykowej - opis przypadku i przegląd piśmiennictwa. Borgis, Nowa Medycyna 2011; 2: 31-33. 